\title{
Influences on catch-up growth using relative versus absolute metrics: evidence from the MAL-ED cohort study
}

Stephanie A. Richard', Benjamin J. J. McCormick', Laura E. Murray-Kolb², Pascal Bessong ${ }^{3}$, Sanjaya K. Shrestha ${ }^{4}$, Estomih Mduma ${ }^{5}$, Tahmeed Ahmed ${ }^{6}$, Gagandeep Kang ${ }^{7}$, Gwenyth O. Lee ${ }^{8}$, Jessica C. Seidman ${ }^{1}$, Erling Svensen ${ }^{9}$, Margaret N. Kosek ${ }^{10}$, Laura E. Caulfield ${ }^{8^{*}}$ (i) and MAL-ED Network Investigators

\begin{abstract}
Background: Poor growth in early childhood has been considered irreversible after 2-3 years of age and has been associated with morbidity and mortality over the short-term and with poor economic and cognitive outcomes over the long-term. The MAL-ED cohort study was performed in eight low-income settings with the goal of evaluating relationships between the child's environment and experience (dietary, illness, and pathogen exposure, among others) and their growth and development. The goal of this analysis is to determine whether there are differences in the factors associated with growth from 24 to 60 months using two different metrics.

Methods: Across six MAL-ED sites, 942 children had anthropometry data at 24 and 60 months, as well as information about socioeconomic status, maternal height, gut permeability (lactulose-mannitol z-score (LMZ)), dietary intake from 9 to 24 months, and micronutrient status. Anthropometric changes were in height- or weightfor-age z-score (HAZ, WAZ), their absolute difference from the growth standard median (HAD (cm), WAD (kg)), as well as recovery from stunting/underweight. Outcomes were modeled using multivariate regression.
\end{abstract}

Results: At 24 months, almost half of the cohort was stunted (45\%) and 21\% were underweight. Among those who were stunted at 24 months $(n=426), 185(43 \%)$ were no longer stunted at 60 months. Most children increased their HAZ from 24 to 60 months (81\%), whereas fewer (33\%) had positive changes in their HAD. Linear regression models indicate that girls improved less than boys from 24 to 60 months (HAZ: - 0.21 (95\% Cl -0.27, -0.15); HAD: -0.75 (-1.07, $-0.43)$ ). Greater intestinal permeability (higher $L M Z$ ) at $0-24$ months was associated with lower relative and absolute changes from 24 to 60 months (HAZ: $-0.10(-0.16,-0.04)$; HAD: $-0.47(-0.73,-0.21))$. Maternal height (per $10 \mathrm{~cm})$ was positively associated with changes (HAZ: $0.09(0.03,0.15)$; HAD: $0.45(0.15,0.75))$. Similar relationships were identified for changes in WAZ and WAD.

Conclusions: The study children demonstrated improved growth from 24 to 60 months of age, but only a subset had positive changes in HAD and WAD. The same environmental factors were associated with growth from 24 to 60 months regardless of metric used (change in HAZ or HAD, or WAZ and WAD).

Keywords: Stunting, Underweight, Catch-up growth, Enteric dysfunction, Permeability

\footnotetext{
* Correspondence: Icaulfi1@jhu.edu

${ }^{8}$ The Johns Hopkins University, 615 North Wolfe Street, Room W2041, Baltimore, MD 21205, USA

Full list of author information is available at the end of the article
}

(C) The Author(s). 2021 Open Access This article is licensed under a Creative Commons Attribution 4.0 International License, which permits use, sharing, adaptation, distribution and reproduction in any medium or format, as long as you give appropriate credit to the original author(s) and the source, provide a link to the Creative Commons licence, and indicate if changes were made. The images or other third party material in this article are included in the article's Creative Commons licence, unless indicated otherwise in a credit line to the material. If material is not included in the article's Creative Commons licence and your intended use is not permitted by statutory regulation or exceeds the permitted use, you will need to obtain permission directly from the copyright holder. To view a copy of this licence, visit http://creativecommons.org/licenses/by/4.0/ The Creative Commons Public Domain Dedication waiver (http://creativecommons.org/publicdomain/zero/1.0/) applies to the data made available in this article, unless otherwise stated in a credit line to the data. 


\section{Background}

Poor growth in early childhood is associated with increased risk of morbidity and mortality [1-4], as well as with longer-term negative effects on cognitive development and economic productivity [5-7]. Scientific evidence over decades of research suggested that in early childhood, growth faltering can be reversed and catchup growth can occur through improved nutrition and other inputs (e.g., reduced disease frequency), but after $2-3$ years of age, such inputs are less likely to result in catch-up growth $[8,9]$. This research emphasized the need for prevention and control of linear growth faltering and stunting in the first 2 years of life, and this has led to a focus on "the first 1000 days", recognizing as well the importance of the maternal nutrition environment for child growth and development [10].

The literature documenting the reduced likelihood of catch-up growth after 2-3 years of age led many to consider that children who were stunted at age 2 years would never exhibit catch-up growth and remain stunted at later ages. There are now numerous studies published in which children with height-for-age z-scores (HAZ) <- 2 (i.e., stunted) in early childhood were found to have HAZ>-2 later in childhood or adolescence [11-15], suggesting that the growth of some children does improve after the age of 2 years. For example, a girl who is approximately $4.5 \mathrm{~cm}$ shorter than the median length at 6 months old is the equivalent of $-2 \mathrm{HAZ}$ (2.3rd percentile), but the same absolute difference in $\mathrm{cm}$ at 24 months old would equate to being - 1.4 HAZ (8th percentile), hence the appearance of a relative recovery toward the median. Leroy et al. [16] made the observation that because normal child growth is heteroscedastic (i.e., the variability of size (height or weight) increases with age), the absolute difference between the median and standard deviation quantiles increases with age. This means that children may continue to grow poorly but their status will fall more within the limits of the distribution. Leroy et al. [16] pointed out that in terms of the absolute difference in height-for-age from the median (HAD, in $\mathrm{cm}$ ), improvements in HAZ over time do not necessarily represent a recovery of centimeters foregone.

This contradiction between apparent gains in HAZ concomitant with greater absolute HAD challenges our understanding of the impact of programs or other influences on child growth during the pre-school period. Since the publication by Leroy et al. [16], researchers have compared differences in HAZ and HAD by age to evaluate this phenomenon $[17,18]$. Here, we use longitudinal data from the Etiology, Risk Factors, and Interactions of Enteric Infections and Malnutrition and the Consequences for Child Health and Development Project (MAL-ED) to evaluate child growth in terms of height and weight (HAZ, HAD, weight-for-age z-score (WAZ), and weight-for-age difference (WAD)) from 24 to 60 months, and to evaluate factors associated with positive changes in relative versus absolute metrics. We ask the following questions: 1) Is there a difference in the assessment of growth from 24 to 60 months when considered in relative versus absolute terms?, and 2) are there differences in the early life factors associated with growth from 24 to 60 months, depending on which metric is used?

\section{Methods}

The overall goal of the MAL-ED longitudinal multi-site birth cohort study was to evaluate the relationships between the child's environment and experience (dietary, illness, and pathogen exposure, among others) and growth and cognitive development from birth to 24 months [19]. It was conducted in eight sites; however, two sites were excluded from this analysis, one because of anthropometric data collection irregularities (Naushero Feroze, Pakistan (PKN)) and one because the cohort's prevalence of children with $\mathrm{HAZ}<-2$ is consistent with the WHO standards (Fortaleza, Brazil (BRF)). The six sites that remained in the analysis were: Dhaka, Bangladesh (BGD); Vellore, India (INV); Bhaktapur, Nepal (NEB); Loreto, Peru (PEL); Venda, South Africa (SAV), and Haydom, Tanzania (TZH). Each site enrolled at least 200 children within 17 days after birth who were born singleton to a mother who was at least 16 years of age, and who weighed at least $1500 \mathrm{~g}$ at birth and considered generally healthy. Enrollment began in November 2009, with follow up through February 2014, and through additional funding, a follow-up of these children at 60 months was completed in February 2017 [20]. The protocols were reviewed by appropriate Institutional Review Boards (IRB) in each site and written consent was obtained from the family, both for the initial protocol, and for the follow-up. More detailed descriptions of the study protocol have been published [21-24]; here we provide details most relevant for these analyses.

\section{Anthropometry}

Trained field workers visited the households monthly to measure child length and weight during the first 24 months of life and at least quarterly thereafter until 60 months [20], although due to funding and IRB approval gaps, this was inconsistently practiced at the sites. The length ( $\leq 24$ months) or height (>24 months), hereafter referred to as height, and weight measures were then converted to sex- and age-specific HAZ and WAZ using the WHO 2006 growth standards [25]. Absolute HAD and WAD were calculated by subtracting the WHO reference median height or weight for a child of the same age and sex from the measured value. Changes in HAZ, 
HAD, WAZ and WAD were calculated by subtracting the 24-month value from the 60 -month value. Field workers additionally measured maternal height 2 months after the child was enrolled in the study. For analyses, children were required to have height and weight values at 0,24 , and 60 months of age, allowing for a \pm 30 -day window. Stunting is defined as $\mathrm{HAZ}<-2$ and underweight is defined as $\mathrm{WAZ}<-2$.

\section{Socioeconomic status}

Household socioeconomic information was collected every 6 months. In order to have a common measure of socioeconomic status across the sites, an indicator was developed combining information on household Water and sanitation status, Assets, Maternal education, and Income (WAMI) [26]. The WAMI index ranges from 0 to 1 , with a higher value indicating a higher socioeconomic status for the household. We calculated the mean WAMI score when the child was 30 and 36 months old in order to best represent their socioeconomic status between 24 and 60 months.

\section{Illness surveillance}

Trained fieldworkers visited the homes bi-weekly during the first 24 months of life to query caregivers about signs and symptoms of morbidity for common illnesses [21]. From this, the prevalence and incidence of diarrhea and respiratory illnesses were calculated. Stool samples were taken during each diarrheal episode and tested to determine etiology [27]. Monthly surveillance stools were also collected and subjected to testing to evaluate pathogen carriage.

\section{Gut function}

The lactulose:mannitol (L:M) test [23] was performed at 3, 6,9 , and 15 months to assess the permeability and absorptive capacity of the gut during the first 24 months of life. We generated age and sex standardized z-scores for the L: $M$ ratios [28] (LMZ) and calculated the mean value of these over the first 24 months of life for each child. A greater value indicates greater enteric dysfunction, using the BRF site as the reference. From each of the monthly (non-diarrheal) surveillance stools, three indicators of gut inflammation and permeability were also assessed: neopterin, myeloperoxidase, and alpha-1-antitrypsin [23].

\section{Diet}

From enrollment to 24 months, during the bi-weekly morbidity surveillance, caregivers were queried about breastfeeding and the feeding of other liquids and solids. From 9 to 24 months, trained field workers utilized a quantitative 24-h recall questionnaire to quantify intakes of non-breast milk foods on a monthly basis [22]. The food intakes were transformed into energy, macro-, and micro-nutrients using study-created food composition databases. Due to co-linearity observed in the dietary data components, only energy intake and the protein density of the diet were included in our analysis. Using the residual method [29], we performed a regression of mean protein intake on mean energy intake and considered the residuals as an indicator of usual protein density. A similar process was used for the intakes of micronutrients included in the supplementary materials in order to derive other measures of the nutrient density in the diet.

\section{Micronutrient status}

Blood samples were taken by venipuncture at 7,15 , and 24 months of age to characterize iron, zinc, and vitamin A status of the child. Plasma concentrations of retinol and zinc were used to characterize vitamin $\mathrm{A}$ and zinc status, respectively. Plasma ferritin and plasma transferrin receptor (TfR) were assessed as indicators of iron status. At each time point, and at 60 months, hemoglobin concentration was obtained using the HemoCue method to detect anemia. Biochemical concentrations were adjusted for inflammation using plasma alpha-1-acid glycoprotein (AGP) [30], and transformed using a square root function.

\section{Statistical methods}

The distributions of HAZ, HAD, WAZ, and WAD were plotted at 0,24 , and 60 months of age. The relationship between changes in HAZ and HAD (and WAZ and WAD) between 24 and 60 months were plotted and quantified with correlation coefficients $(r)$. Children were identified as stunted or underweight at 24 and 60 months and these categories were used to identify the persistence of or recovery from stunting and underweight status. We used linear regression, controlling for study site, to evaluate factors associated with changes in in HAZ, HAD, WAZ, and WAD. Based on previous analyses of factors related to growth [20,31, 32], socioeconomic status (WAMI), child's sex, study site, maternal height, and the value of HAZ, HAD, WAZ or WAD at 24 months were included in each base model. We used biologic rationale, data completeness, and stepwise selection (forward and backward improvements to the Akaike Information Criterion (AIC)) to identify other variables for inclusion, which were tested in a model that included all variables in the base model, plus the variable under consideration. A list of the variables that were considered can be found in the supplemental materials (Supplemental Table 1). Models were run in R 3.4.3 (Foundation for Statistical Computing, Vienna, Austria). 


\section{Results}

Among the 1635 children enrolled in the six MAL-ED sites included in these analyses, 1040 (64\%) had anthropometry at 0,24 , and 60 months of age, and the sample size decreased to 942 (58\%) when we required that the children have at least one observation for each of key variables found to be associated with growth outcomes at 60 months in a previous publication using data from this cohort [20]: transferrin receptor, LMZ, maternal height, WAMI, and dietary intake 9-24 months (Fig. 1). We compared the baseline HAZ, WAZ, and WAMI scores between those who were included in the analysis and those who were not and found no statistically significant differences for LAZ at enrollment and mean WAMI scores, but the WAZ at enrollment were statistically significantly lower for those included in this analysis than in those who were not (Supplemental Table 2).

HAZ values were highest at enrollment, lowest at 24 months, and intermediate at 60 months (Fig. 2 and Table 1). WAZ values were also highest at enrollment, but the values at 24 and 60 months were overlapping.
HAD and WAD values were smallest (closer to median) at enrollment and became larger at 24 and at 60 months.

Just under half of the children included in this analysis were stunted at 24 months (Table 2), and approximately one-fifth of the children were underweight at 24 months. Children who were not stunted or underweight at 24 months were unlikely to be stunted or be underweight at 60 months (Table 3). Category switches from stunted to non-stunted (and underweight to non-underweight) were common between 24 and 60 months.

Shown in Fig. 3 are the patterns of mean HAZ and HAD amongst those who were never stunted, those who remained stunted and those who recovered from stunting. A figure capturing these same relationships for WAZ and WAD is also shown. Among those who were stunted or underweight throughout, the mean HAD or WAD continued to decrease until nearly 60 months, but flattened out at around 24 months of age for those who were no longer stunted or underweight at 60 months. Changes in HAZ and HAD between 24 and 60 months were highly correlated $(r=0.80)$, as were changes in WAZ and WAD $(r=0.77)$ (Fig. 4).

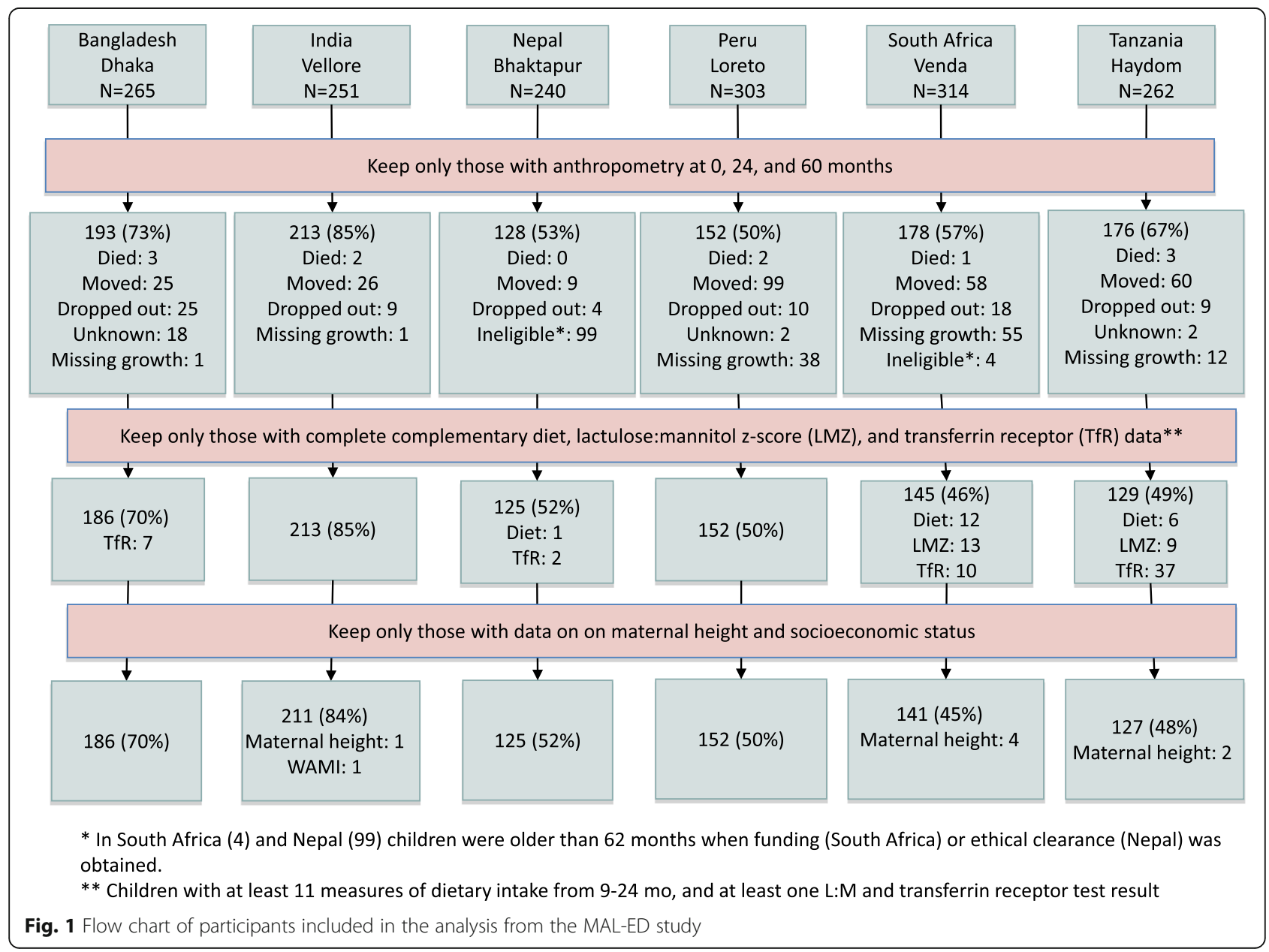



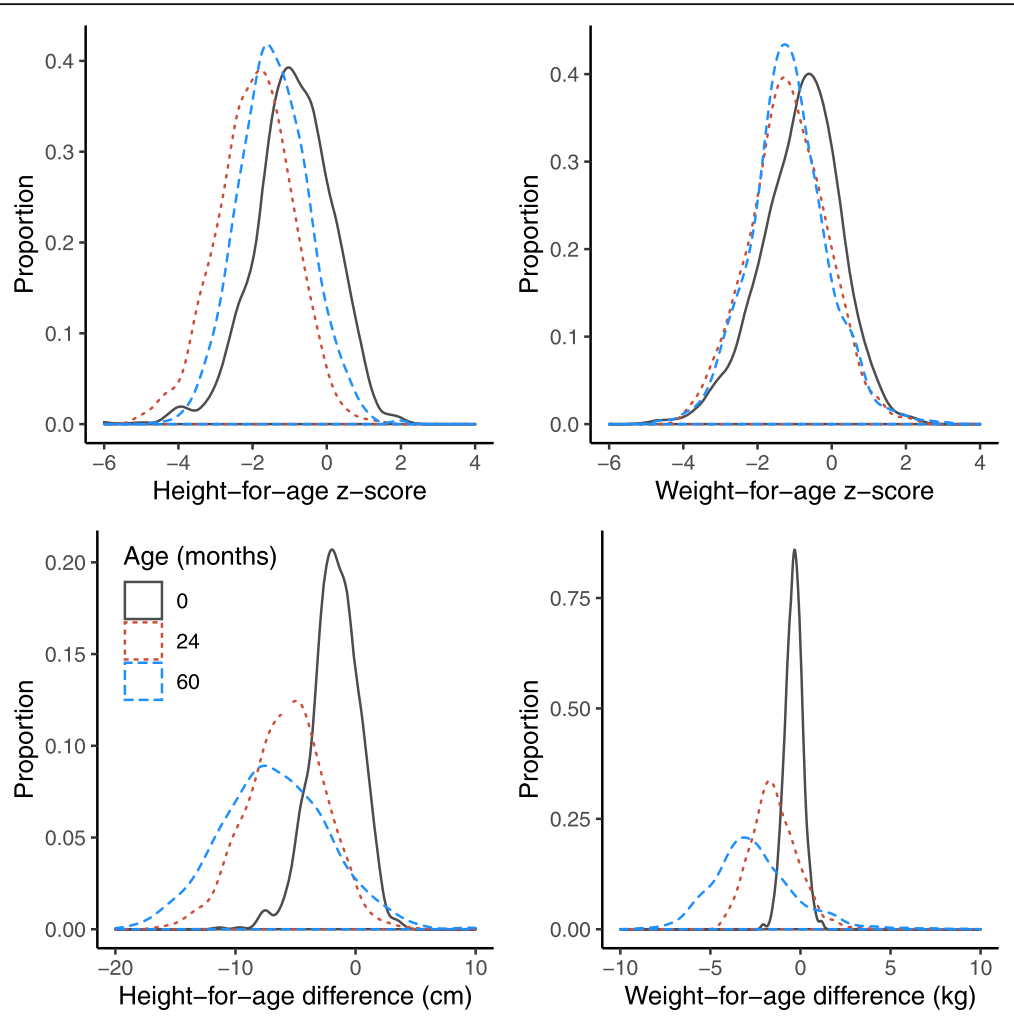

Fig. 2 Probability distributions of height-for-age $z$-scores (HAZ), weight-for-age $z$-scores (WAZ), and weight-for-height z-scores (WHZ) at 0, 24, and 60 months in the MAL-ED cohort study sites

Most children had a positive change in their HAZ from 24 to 60 months, whereas far fewer had a positive change (smaller difference from median) in their HAD (Table 2). In general, positive changes in WAZ and WAD were less common than for HAZ and HAD.

Results of multivariable linear regression models adjusted for HAZ or HAD at 24 months indicate that child's sex, maternal height, and mean LMZ were both associated with change in HAZ, HAD, WAZ and WAD from 24 to 60 months (Table 3). Greater average LMZ, a marker of intestinal permeability, was negatively associated with changes in both HAZ and HAD from 24 to 60 months. Results were similar, although not always statistically significant for the Poisson regression models considering positive changes in HAZ or HAD as the outcome variable (Supplemental Table 3). Higher mean TfR in the first 24 months of life was associated positively with changes in WAZ and WAD, whereas the average protein density from complementary foods was negatively associated with changes in WAZ and WAD from 24 to 60 months. WAMI (a measure of socioeconomic status) was positively associated with changes in WAZ and WAD, but when the binary outcomes were considered (positive change in WAZ or WAD, recovery from underweight), the associations with WAMI were not statistically significant (Supplemental Table 3).

\section{Discussion}

Populations with a high prevalence of stunting tend to have height distributions that are negatively shifted, rather than skewed, compared with the standard WHO distribution. This suggests that the entire population, rather than a subset, is not growing to their potential [33]. In these data, from 24 to 60 months of age, the distribution of HAZ shifted to the right, indicating a positive change in height relative to their position at 24 months. However, as has been demonstrated in other studies [16, $18]$, the HAD distribution shifted further to the left from 24 to 60 months of age, indicating that children had greater absolute height deficits at 60 months than they had at 24 months when compared with the WHO median. For weight, the distributions of WAZ at 24 and 60 months were very similar, whereas the WAD distribution shifted more to the left from 24 to 60 months, indicating greater weight deficits at 60 months.

As discussed earlier, the apparent contradiction between relative and absolute height and weight deficits stems from the increasing variance of normal child growth which is depicted in the WHO z-score calculations. Leroy et al. [16] have suggested that HAD is a more meaningful way to measure catch-up growth in a population, whereas Victora et al. [34] argued that changes in HAZ and HAD are both meaningful ways to 
Table 1 Characteristics of children with anthropometry at 0, 24, and 60 months of age in the MAL-ED study, including heightfor-age z-score (HAZ), height-for-age difference (HAD), weightfor-age $z$-score (WAZ), and weight-for-age difference (WAD). Stunting is defined as $\mathrm{HAZ}<-2$, underweight is defined as WAZ $<-2$

\begin{tabular}{|c|c|}
\hline $\mathrm{N}$ & 942 \\
\hline No. girls (\%) & $474(50.3)$ \\
\hline Mean SES score ${ }^{\mathrm{a}}(\mathrm{SD})$ & $0.6(0.2)$ \\
\hline Mean Lactulose:Mannitol z-score ${ }^{\mathrm{b}}$ (SD) & $0.4(0.6)$ \\
\hline Maternal height, cm (SD) & $152.2(6.5)$ \\
\hline Mean energy intake ${ }^{c}, \mathrm{kcal} / \mathrm{d}$ (SD) & $838.0(360.8)$ \\
\hline Mean protein intake ${ }^{c}, \mathrm{~g} / \mathrm{d}(\mathrm{SD})$ & $23.3(10.5)$ \\
\hline Mean transferrin receptor ${ }^{d}, \mathrm{mg} / \mathrm{L}(\mathrm{SD})$ & $6.0(3.1)$ \\
\hline \# stunted at 0 mo (\%) & $130(13.8)$ \\
\hline \# stunted at $24 \mathrm{mo}(\%)$ & $426(45.2)$ \\
\hline \# stunted at 60 mo (\%) & $256(27.2)$ \\
\hline Mean HAZ at 0 mo (SD) & $-0.9(1.0)$ \\
\hline Mean HAZ at 24 mo (SD) & $-1.9(1.0)$ \\
\hline Mean HAZ at 60 mo (SD) & $-1.4(0.9)$ \\
\hline Change HAZ 24 to 60 mo (SD) & $0.5(0.6)$ \\
\hline Change HAD 24 to $60 \mathrm{mo}(\mathrm{cm})$ & $-1.0(2.5)$ \\
\hline \# underweight at 0 mo (\%) & $130(13.8)$ \\
\hline \# underweight at 24 mo (\%) & $202(21.4)$ \\
\hline \# underweight at 60 mo (\%) & $184(19.5)$ \\
\hline Mean WAZ at 0 mo (SD) & $-0.8(1.1)$ \\
\hline Mean WAZ at 24 mo (SD) & $-1.2(1.0)$ \\
\hline Mean WAZ at 60 mo (SD) & $-1.2(1.0)$ \\
\hline Change WAZ 24 to 60 mo (SD) & $0.0(0.7)$ \\
\hline Change WAD 24 to 60 mo (kg) & $-1.1(1.6)$ \\
\hline
\end{tabular}

${ }^{a}$ Socioeconomic score is the mean of values at 30 and 36 months. The score was generated for the MAL-ED study and based on Water and sanitation, Assets, Maternal education, and Income (WAMI) [26]

b Lactulose:Mannitol tests were conducted 3, 6, 9 and 15 months and transformed into z-scores, and the mean of 1-4 z-scores was calculated per child

'Represents the mean intake per child of non-breast milk foods assessed monthly from 9 to 24 months (range 11-17 assessments per child)

${ }^{d}$ Mean of 1-3 measures per child assessed at 7, 15, and 24 months

express changes in linear growth in children, and that they give complementary information. Here we have shown that in low-income settings, children who show positive changes in HAD are a subset of those who show positive changes in HAZ and are more likely to be those with greater positive changes in HAZ. This is also true for WAZ and WAD, except that positive changes in WAD are much less likely to be observed. Because of the overall high correlation between the changes in the indicators from 24 to 60 months (as shown in Fig. 4), it is not surprising that we did not identify factors in early life that distinguish between these two types of changes over time. Given the similarity of the factors associated with change in HAZ and HAD from 24 to 60 months (child sex, maternal height, and LMZ), both metrics are informative when evaluating environmental influences on the growth of children.

Maternal height was associated positively with change in each of the four metrics from 24 to 60 months. For linear growth (change in HAZ), the association is smaller in effect size but consistent with findings by Addo et al. [35] of positive associations between maternal height and linear growth from 24 months to mid-childhood in five low- and middle-income countries. Here we extend that finding by showing positive associations with change in HAD. As discussed by Addo et al. [35], the persistence of associations between maternal height and linear and somatic growth likely reflect genetic and nongenetic factors as well as intergenerational factors.

Greater average LMZ was associated with negative changes in each of the four outcomes from 24 to 60 months. Greater LMZ is generally regarded as a measure of environmental enteric dysfunction (EED). Previously, we have demonstrated small negative associations with linear growth velocity in the first 24 months of life [36], but statistically significant negative associations with both attained HAZ and WAZ at 60 months [20]. The results here are consistent with this latter finding. Whether EED in early childhood has long-term negative consequences for child growth throughout the preschool period or whether average LMZ during the first 24 months is a marker for EED from 24 to 60 months is not known.

This hypothesis may also explain findings related to TfR. Previously we have shown positive associations between mean TfR in early childhood and attained WAZ and HAZ at 60 months [20]. Here, the direction of the results is consistent, but the associations are statistically significant for WAZ and WAD only. It is known that TfR is elevated with iron-deficient erythropoiesis and with inflammation (which we adjusted for using AGP), but it is also known to be elevated with cellular proliferation, including erythropoiesis during periods of growth. Thus, associations of TfR in early childhood with growth may reflect greater cellular proliferation, the underlying cause of which is not known. Why variability would be uniquely associated positively with changes in WAZ and WAD from 24 to 60 months requires further research.

That the protein density of complementary foods was negatively associated with changes in WAZ and WAD from 24 to 60 months is somewhat surprising because the same measure was found to be positively associated with growth in weight and length through 24 months [32]. Findings from prior studies (reviewed by Michaelsen and Greer [37]) suggest that higher protein intakes before age 2 years are associated with greater BMI at 4 years of age and older. These findings may not be 
Table 2 Summary of transitions between stunted and non-stunted status, and underweight and non-underweight status at 24 and 60 months in the cohort. Number (\%) of children with positive changes in growth (linear and ponderal), defined as positive change in height-for-age z-score (HAZ), weight-for-age z-score (WAZ), height-for-age difference (HAD), or weight-for-age difference (WAD), and recovery from stunting $(\mathrm{HAZ}<-2)$ or underweight $(\mathrm{WAZ}<-2)$. Changes were calculated by subtracting the value at 24 months from the value at 60 months of age. Stunting is defined as height-for-age $z$-score $(H A Z)<-2$, underweight is defined as weight-forage $z$-score $(W A Z)<-2$

\begin{tabular}{llll}
\hline Height & N (\%) & Weight & N (\%) \\
\hline Not stunted at 24 or 60 months & $501(53)$ & Not underweight at 24 or 60 months & 689 (73) \\
Not stunted at 24, stunted at 60 months & $15(2)$ & Not underweight at 24, underweight at 60 months & $51(5)$ \\
Stunted at 24, not at 60 months & $185(20)$ & Underweight at 24, not at 60 months & Underweight at both 24 and 60 months \\
Stunted at both 24 and 60 months & $241(26)$ & Positive change in WAZ & 133(14) \\
Positive change in HAZ & $763(81)$ & Positive change in WAD & 166 (18) \\
Positive change in HAD & $308(33)$ & Recovery from underweight & 69/202 (34) \\
Recovery from stunting & $185 / 426(43)$ & &
\end{tabular}

generalizable to our study children for several reasons. The majority of children in MAL-ED were breastfed through $18+$ months of life. Animal milks contributed to the overall protein density of their diet during the first 24 months, but the protein intakes (\% energy) were on the order of $10-12 \%$, and the frequency of animal milk consumption declined $>24$ months.

One of the primary strengths of this study is the longitudinal data that allow for detailed analysis of growth in early childhood across six sites with high rates of stunting. The extensive data on risk factors collected during the study allow for evaluation of risk factors for growth across different categories, measured in a common way across the sites. However, there are also some limitations to this analysis. Iron deficiency may be underestimated because we adjusted for inflammation using only one marker. There are community-level factors that likely affect the growth of all children at a site, as well as other unmeasured risk factors, and those contribute to the unexplained variance of our models. In addition, the gaps in funding and IRB approvals for the follow up study led to inconsistencies in data collection across sites depending on whether sites could maintain field activities during the gap period and resulted in many children with missing data in some sites. Thus, our analyses necessarily focus on factors assessed during the first 24 months of life, and it may be that longitudinal data sets with more extensive data from 24 to 60 months may be able to identify specific factors during that period associated with positive changes in HAD amongst those with positive changes in HAZ over time. There was considerable loss to follow-up between 2 and 5 years, and this limited our sample size. When we compared some key characteristics, those who were lost to follow up or excluded

Table 3 Results from linear regression models with the outcomes of height-for-age z-score (HAZ), height-for-age difference (HAD), weight-for-age z-score (WAZ), and weight-for-age difference (WAD) change between 24 and 60 months as a function of anthropometry at 24 months and other child and household factors in six sites from the MAL-ED study (BGD, INV, NEB, PEL, SAV, $\mathrm{TZH})$

\begin{tabular}{|c|c|c|c|c|}
\hline & \multicolumn{4}{|c|}{$\Delta 24$ to $60 \mathrm{mo}(n=942)$} \\
\hline & $\Delta \mathrm{HAZ}$ (SE) & $\triangle \mathrm{HAD}(\mathrm{SE})$ & $\triangle \mathrm{WAZ}$ (SE) & $\triangle W A D(S E)$ \\
\hline $\mathrm{HAZ}$ at $24 \mathrm{mo}$ & $-0.25(0.02)^{* * *}$ & & & \\
\hline HAD at 24 mo & & $0.12(0.03)^{* * *}$ & & \\
\hline WAZ at $24 \mathrm{mo}$ & & & $-0.26(0.02)^{* * *}$ & \\
\hline WAD at 24 mo & & & & $0.33(0.04)^{* * *}$ \\
\hline SES score, $30-36$ mo (10\% increase) & $0.01(0.01)$ & $0.03(0.06)$ & $0.04(0.02)^{*}$ & $0.09(0.04)^{*}$ \\
\hline Boys 0, Girls 1 & $-0.21(0.03)^{* * *}$ & $-0.75(0.16)^{* * *}$ & $-0.16(0.04)^{* * *}$ & $-0.48(0.09)^{* * *}$ \\
\hline Maternal height (per $10 \mathrm{~cm}$ ) & $0.09(0.03)^{* *}$ & $0.45(0.15)^{* *}$ & $0.10(0.04)^{*}$ & $0.22(0.09)^{*}$ \\
\hline Mean Lactulose:Mannitol z-score & $-0.10(0.03)^{* * *}$ & $-0.47(0.13)^{* * *}$ & $-0.13(0.03)^{* * *}$ & $-0.28(0.08)^{* * *}$ \\
\hline Mean energy intake 9-24 mo & $0.01(0.02)$ & $0.07(0.08)$ & $-0.02(0.02)$ & $-0.02(0.05)$ \\
\hline Protein density 9-24 mo & $-0.01(0.02)$ & $-0.03(0.08)$ & $-0.05(0.02)^{*}$ & $-0.11(0.05)^{*}$ \\
\hline Mean transferrin receptor, inflammation adjusted [30] & $0.00(0.01)$ & $0.01(0.03)$ & $0.02(0.01)^{*}$ & $0.04(0.02)^{*}$ \\
\hline
\end{tabular}

${ }^{* * *} p<0.001,{ }^{* *} p<0.01,{ }^{*} p<0.05$ 


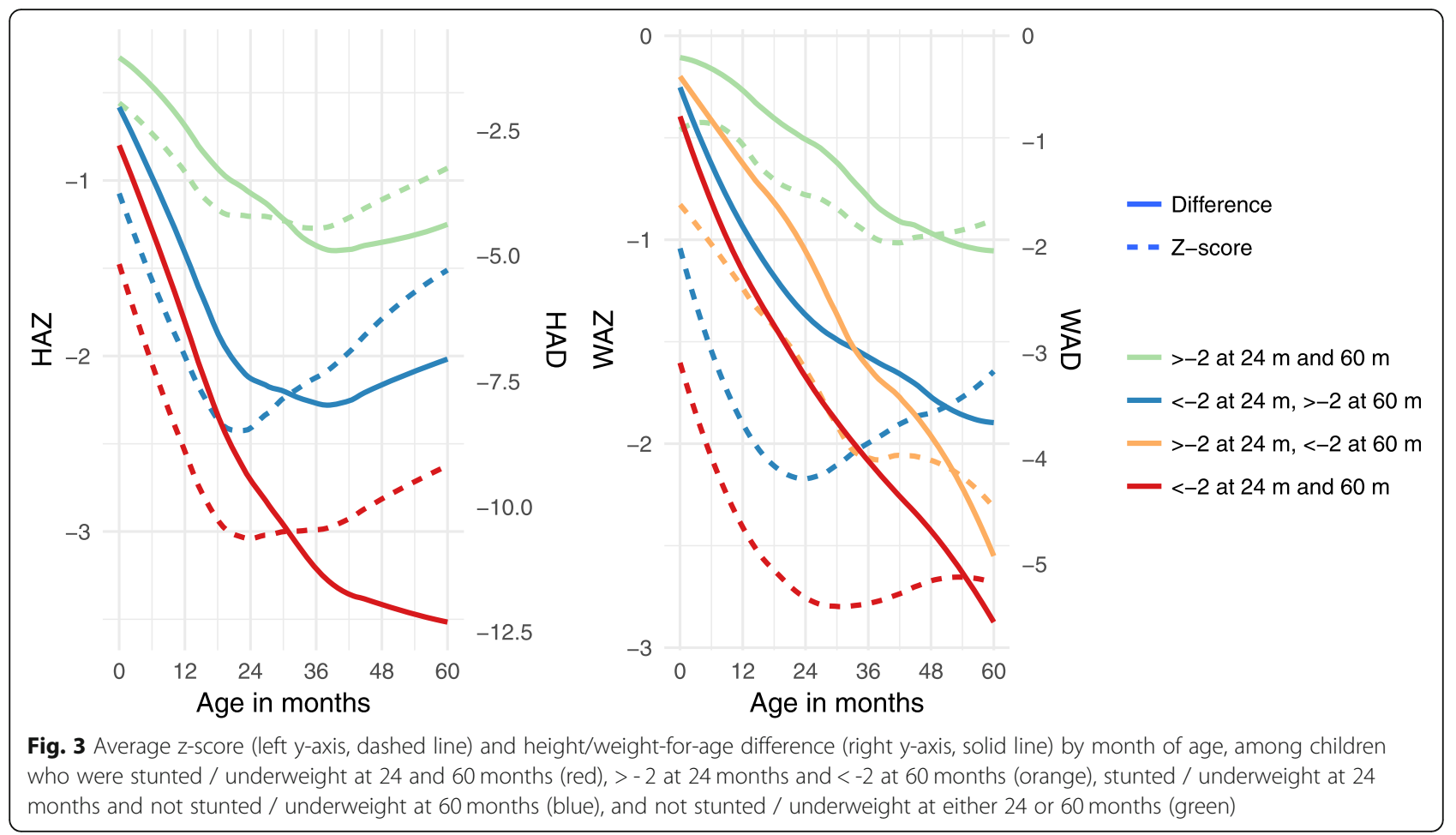

due to missing variables were similar with respect to mean LAZ at enrollment and socioeconomic status, but had statistically significantly higher WAZ at enrollment than did those who were retained. We expect that the WAZ difference is primarily due to differential follow up at sites (the South African and Peruvian sites had higher WAZ at enrollment than the other sites and higher loss to follow up); because we are controlling for site in the analysis, we expect that to have little effect on our results.

\section{Conclusions}

In six MAL-ED sites, almost half (43\%) of the children who were stunted at 24 months of age were no longer stunted at 60 months of age, indicating some degree of
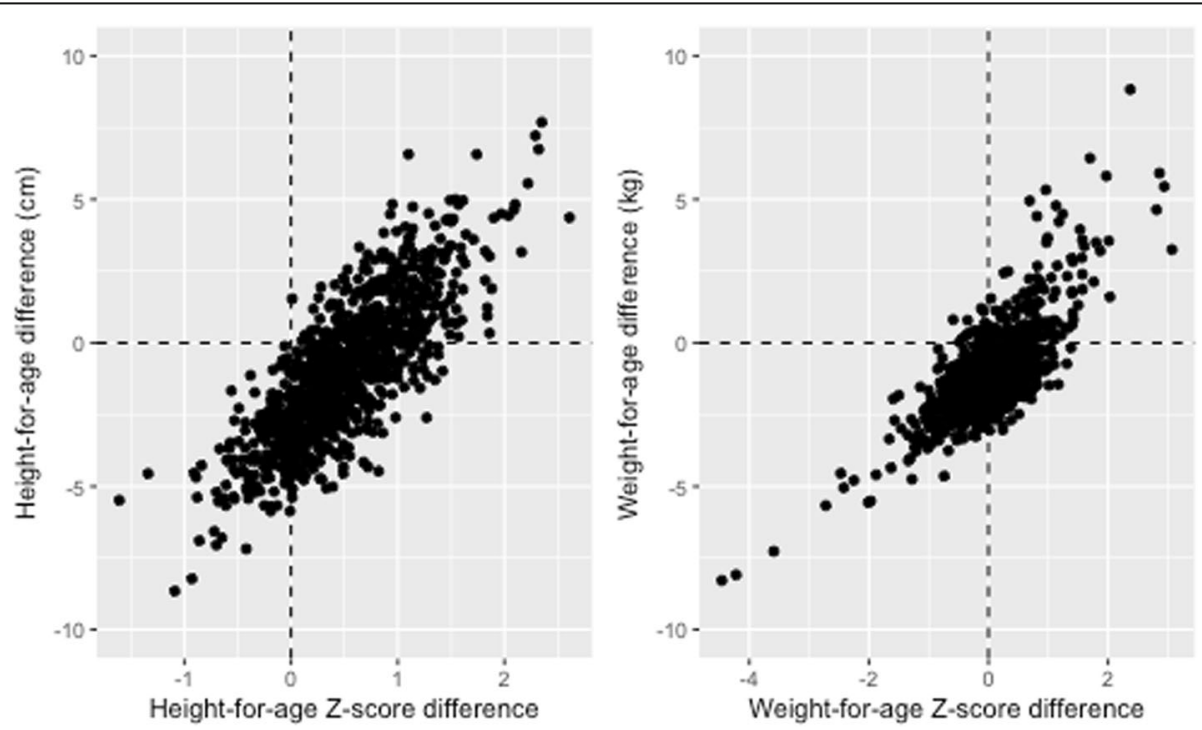

Fig. 4 Difference in height/weight-for-age z-scores and height/weight-for-age centimeters/kilograms between 24 and 60 months of age at six MAL-ED sites 
improvement in linear growth from 24 to 60 months. Very few children developed stunting after 24 months of age. Most of the children demonstrated some improvement in HAZ, and except for SAV, only about $30 \%$ had improvement in HAD. Fewer children had a positive change in WAZ, and most of the children with a positive WAD were in the sites in Peru and South Africa. Given the high correlation and the similarity in factors associated with changes in z-scores or absolute difference, we conclude that both approaches can be used to understand factors associated with child growth from 24 to 60 months.

\section{Abbreviations}

BGD: Dhaka, Bangladesh; BRF: Fortaleza, Brazil; HAD: Height-for-age difference; HAZ: Height-for-age z-score; INV: Vellore, India; LAZ: Length-forage z-score; LMZ: Lactulose:mannitol z-score; NEB: Bhaktapur, Nepal; PEL: Loreto, Peru; PKN: Naushero Feroze, Pakistan; SAV: Venda, South Africa; TfR: Transferrin receptor; TZH: Haydom, Tanzania; WAMI: Water, Assets, Maternal education, and household Income; WAD: Weight-for-age difference; WAZ: Weight-for-age z-score

\section{Supplementary Information}

The online version contains supplementary material available at https://doi. org/10.1186/s12889-021-11120-0.

Additional file 1.

\section{Acknowledgements}

The Etiology, Risk Factors and Interactions of Enteric Infections and Malnutrition and the Consequences for Child Health and Development Project (MAL-ED) was a collaborative project led by the Foundation for the National Institutes of Health and the National Institutes of Health, Fogarty International Center. The findings and conclusions in this report are those of the authors and do not necessarily represent the official position of the U.S. National Institutes of Health or Department of Health and Human Services.

\section{Authors' contributions}

SAR, BJJM, LEMK, and LEC designed the research, contributed to the analysis and interpretation of results, and wrote the manuscript. JCS and GOL contributed to the conceptualization of the research questions and analysis, and JCS, SAR and BJJM contributed data science through MAL-ED Data Coordinating Center. SAR performed the statistical analysis. TA, GK, EM, ES, MNK, SKS, and PB conducted the research. SAR and LEC have primary responsibility for final content, and all authors reviewed the manuscript. A full listing of all MAL-ED Network Investigators is provided at the end of the manuscript. The corresponding author attests that all listed authors meet authorship criteria and that no others meeting the criteria have been omitted. The authors read and approved the final manuscript.

\section{Authors' information}

MAL-ED Network Investigators and Institutional Affiliations

Angel Mendez Acosta

Rosa Rios de Burga ${ }^{\top}$

Cesar Banda Chavez

Julian Torres Flores ${ }^{1}$

Maribel Paredes Olotegui

Silvia Rengifo Pinedo

Mery Siguas Salas ${ }^{1}$

Dixner Rengifo Trigoso'

Angel Orbe Vasquez ${ }^{1}$

Imran Ahmed ${ }^{2}$

Didar Alam² $^{2}$

Asad $\mathrm{Ali}^{2}$

Zulfigar A Bhutta ${ }^{2}$

Shahida Qureshi
Muneera Rasheed ${ }^{2}$

Saijid Soofi ${ }^{2}$

Ali Turab ${ }^{2}$

Aisha Yousafzai ${ }^{2}$

Anita KM Zaidi ${ }^{25}$

Ladaporn Bodhidatta ${ }^{3}$

Geetha Ammu ${ }^{4}$

Sudhir Babji ${ }^{4}$

Anuradha Bose

Ajila T George ${ }^{4}$

Dinesh Hariraju ${ }^{4}$

M. Steffi Jennifer ${ }^{4}$

Sushil John ${ }^{4}$

Shiny Kaki ${ }^{4}$

Gagandeep Kang ${ }^{4}$

Priyadarshani Karunakaran ${ }^{4}$

Beena Koshy ${ }^{4}$

Robin P Lazarus ${ }^{4}$

Jayaprakash Muliyil ${ }^{4}$

Preethi Ragasudha ${ }^{4}$

Mohan Venkata Raghava ${ }^{4}$

Sophy Raju ${ }^{4}$

Anup Ramachandran ${ }^{4}$

Rakhi Ramadas ${ }^{4}$

Karthikeyan Ramanujam ${ }^{4}$

Anuradha Rose ${ }^{4}$

Reeba Roshan ${ }^{4}$

Srujan L Sharma ${ }^{4}$

Shanmuga Sundaram $E^{4}$

Rahul J Thomas ${ }^{4}$

William K $\mathrm{Pan}^{5}$

Ramya Ambikapathi ${ }^{15}$

J Daniel Carreon ${ }^{6}$

Viyada Doan ${ }^{6}$

Christel Hoest ${ }^{6}$

Stacey Knobler ${ }^{6}$

Benjamin JJ McCormick ${ }^{6}$

Monica McGrath ${ }^{13}$

Mark A Miller ${ }^{6}$

Stephanie Psaki ${ }^{6,26}$

Zeba Rasmussen ${ }^{6}$

Stephanie A Richard ${ }^{6}$

Jessica C Seidman ${ }^{6}$

Michael Gottlieb ${ }^{7}$

Dennis R Lang ${ }^{7}$

Karen $\mathrm{H}_{\text {Tountas }}{ }^{7}$

Erling Svensen ${ }^{8}$

Caroline Amour ${ }^{9}$

Eliwaza Bayyo ${ }^{9}$

Estomih R Mduma ${ }^{9}$

Regisiana Mvungi $i^{9}$

Rosemary Nshama ${ }^{9}$

John Pascal ${ }^{9}$

Buliga Mujaga Swema9

Ladislaus Yarrot ${ }^{9}$

Carl J Mason ${ }^{10}$

Tahmeed Ahmed ${ }^{11}$

AM Shamsir Ahmed ${ }^{11}$

Md Ashraful Alam ${ }^{11}$

Rashidul Haque ${ }^{11}$

Umma Haque ${ }^{11}$

Md lqbal Hossain ${ }^{11}$

Munirul Islam ${ }^{11}$

Mustafa Mahfuz ${ }^{11}$

Dinesh Mondal ${ }^{11}$

Baitun Nahar ${ }^{11}$

Fahmida Tofail $^{11}$

Ram Krishna Chandyo ${ }^{27}$

Prakash Sunder Shrestha ${ }^{12}$

Rita Shrestha ${ }^{12}$

Manjeswori Ulak ${ }^{12}$ 
Aubrey Bauck ${ }^{26}$

Robert E Black ${ }^{13}$

Laura E Caulfield ${ }^{13}$

William Checkley ${ }^{13}$

Margaret N Kosek ${ }^{13}$

Gwenyth O Lee ${ }^{21}$

Kerry Schulze ${ }^{13}$

Pablo Peñataro Yori ${ }^{13}$

Laura E. Murray-Kolb ${ }^{16}$

A Catharine Ross ${ }^{16}$

Barbara Schaefer ${ }^{16}$

Suzanne Simons ${ }^{16}$

Laura Pendergast ${ }^{17}$

Cláudia B Abreu ${ }^{18}$

Hilda Costa ${ }^{18}$

Alessandra Di Moura ${ }^{18}$

José Quirino Filho ${ }^{18}$

Alexandre Havt ${ }^{18}$

Álvaro M Leite ${ }^{18}$

Aldo AM Lima' ${ }^{18}$

Noélia L Lima ${ }^{18}$

lla F Lima ${ }^{18}$

Bruna LL Maciel ${ }^{18}$

Pedro HQS Medeiros ${ }^{18}$

Milena Moraes ${ }^{18}$

Francisco S Mota ${ }^{18}$

Reinaldo B Oriá ${ }^{18}$

Josiane Quetz ${ }^{18}$

Alberto M Soares ${ }^{18}$

Rosa MS Mota ${ }^{18}$

Crystal L Patil ${ }^{20}$

Pascal Bessong 22

Cloupas Mahopo ${ }^{22}$

Angelina Maphula 22

Emanuel Nyathi ${ }^{22}$

Amidou Samie ${ }^{22}$

Leah Barrett ${ }^{23}$

Rebecca Dillingham ${ }^{23}$

Jean $\mathrm{Gratz}^{23}$

Richard L Guerrant ${ }^{23}$

Eric Houpt ${ }^{23}$

William A Petri, Jr23

James Platts-Mills ${ }^{23}$

Elizabeth Rogawski ${ }^{23}$

Rebecca Scharf ${ }^{23}$

Elizabeth T Rogawski ${ }^{23}$

Binob Shrestha ${ }^{24}$

Bishnu Bahadur Rayamajhi24

Sanjaya Kumar Shrestha ${ }^{24}$

Tor Strand ${ }^{19}$

Institutions

A.B. PRISMA, Iquitos, Peru

${ }^{2}$ Aga Khan University, Karachi, Pakistan

${ }^{3}$ Armed Forces Research Institute of Medical Sciences (AFRIMS), Bangkok,

Thailand

${ }^{4}$ Christian Medical College, Vellore, India

${ }^{5}$ Duke University, Durham, NC, USA

${ }^{6}$ Fogarty International Center/National Institutes of Health, Bethesda, MD,

${ }^{7}$ Foundation for the National Institutes of Health, Bethesda, MD, USA

${ }^{8}$ Haukeland University Hospital, Bergen, Norway

${ }^{9}$ Haydom Lutheran Hospital, Haydom, Tanzania

${ }^{10}$ Henry M Jackson Foundation for the Advancement of Military Medicine, Bethesda, MD, USA

${ }^{11}$ icddr,b, Dhaka, Bangladesh

${ }^{12}$ Institute of Medicine, Tribhuvan University, Kathmandu, Nepal

${ }^{13}$ Johns Hopkins University, Baltimore, MD, USA

${ }^{15}$ Purdue University, Department of Nutrition Science, IN, USA

${ }^{16}$ The Pennsylvania State University, University Park, PA, USA

${ }^{17}$ Temple University, Philadelphia, PA, USA

${ }^{18}$ Universidade Federal do Ceara, Fortaleza, Brazil
${ }^{19}$ University of Bergen, Norway

${ }^{20}$ University of Illinois at Chicago, IL, USA

${ }^{21}$ University of Michigan, Department of Epidemiology, MI, USA

${ }^{22}$ University of Venda, Thohoyandou, South Africa

${ }^{23}$ University of Virginia, Charlottesville, VA, USA

${ }^{24}$ Walter Reed/AFRIMS Research Unit, Kathmandu, Nepal

${ }^{25}$ Bill and Melinda Gates Foundation, Seattle, WA, USA

${ }^{26}$ Leland Hunger Fellows Program, Congressional Hunger Center,

Washington DC, USA

${ }^{27}$ Kathmandu Medical College, Kathmandu, Nepal

\section{Funding}

The MAL-ED study was supported by the Bill \& Melinda Gates Foundation, through grants to the Foundation for the National Institutes of Health, and with additional support from the National Institutes of Health, Fogarty International Center. The funder had no direct role in the writing of the manuscript or in the study design, data collection, analysis or interpretation of study results.

We are grateful to the children and caregivers who participated in the study for their invaluable contributions.

\section{Availability of data and materials}

The dataset supporting the analyses presented here can be obtained by requesting the data from the corresponding author. We are not posting this specific file in a repository because data from the MAL-ED study are publicly available (upon request) through the ClinEpiDB platform (https://clinepidb. org). The link to the specific record to explore study data and request a download of the data is https://clinepidb.org/ce/app/record/dataset/DS_5 c41b87221

\section{Declarations}

\section{Ethics approval and consent to participate}

The study was conducted in accordance with the Declaration of Helsinki. Field workers explained the study protocol and obtained written informed consent from a parent or guardian for the children enrolled in the original study, and again for the follow-up study.

The study was approved by the following institutional review boards which correspond to each site and to collaborating institutions: Institutional Review Board for Health Sciences Research, University of Virginia, Charlottesville, Virginia, USA; the Committee for Ethics in Research, Universidade Federal do Ceara; National Ethical Research Committee, Health Ministry, Council of National Health in Brasília and Fortaleza - Brazil (Brazil site); Institutional Review Board, Johns Hopkins Bloomberg School of Public Health, Baltimore, Maryland, USA; PRISMA Ethics Committee; Health Ministry, in Loreto - Peru (Peru site); Health, Safety and Research Ethics Committee, University of Venda; Department of Health and Social Development, Limpopo Provincial Government, in Venda, South Africa (South Africa site); Medical Research Coordinating Committee, National Institute for Medical Research; Chief Medical Officer, Ministry of Health and Social Welfare in Haydom, Tanzania (Tanzania site); Ethical Review Committee, Aga Khan University (Pakistan site); Ethical Review Committee, ICDDR, B in Dhaka - Bangladesh (Bangladesh site); Institutional Review Board, Christian Medical College in Vellore - India and the Health Ministry Screening Committee, Indian Council of Medical Research (India site); Institutional Review Board, Institute of Medicine, Tribhuvan University; Ethical Review Board, Nepal Health Research Council; Institutional Review Board, Walter Reed Army Institute of Research in Bhaktapur - Nepal (Nepal site).

\section{Consent for publication}

Not applicable.

\section{Competing interests}

The authors declare that they have no competing interests.

\section{Author details}

${ }^{1}$ Fogarty International Center/National Institutes of Health, Bethesda, MD, USA. ${ }^{2}$ The Pennsylvania State University, University Park, PA, USA. ${ }^{3}$ University of Venda, Thohoyandou, South Africa. ${ }^{4}$ Walter Reed, Armed Forces Research Institute of Medical Sciences (AFRIMS) Research Unit, Nepal, (WARUN), Kathmandu, Nepal. ${ }^{5}$ Haydom Lutheran Hospital, Haydom, Manyara, Tanzania. 
${ }^{6}$ icddr,b, Dhaka, Bangladesh. ${ }^{7}$ Division of Gastrointestinal Sciences, Christian Medical College, Vellore, Tamil Nadu, India. ${ }^{8}$ The Johns Hopkins University, 615 North Wolfe Street, Room W2041, Baltimore, MD 21205, USA. 'Haukeland University Hospital, Bergen, Norway. ${ }^{10}$ University of Virginia, Charlottesville, VA, USA.

Received: 21 May 2020 Accepted: 24 May 2021

Published online: 29 June 2021

\section{References}

1. Scrimshaw NS. Historical concepts of interactions, synergism and antagonism between nutrition and infection. J Nutr. 2003;133(1):316S-21S https://doi.org/10.1093/jn/133.1.316S.

2. Caulfield LE, de Onis M, Blossner M, Black RE. Undernutrition as an underlying cause of child deaths associated with diarrhea, pneumonia, malaria, and measles. Am J Clin Nutr. 2004;80(1):193-8. https://doi.org/10.1 093/ajcn/80.1.193.

3. Olofin I, McDonald CM, Ezzati M, Flaxman S, Black RE, Fawzi WW, et al. Associations of suboptimal growth with all-cause and cause-specific mortality in children under five years: a pooled analysis of ten prospective studies. PLoS One. 2013;8(5):e64636. https://doi.org/10.1371/journal.pone. 0064636.

4. Black RE, Allen LH, Bhutta ZA, Caulfield LE, de Onis M, Ezzati M, et al. Maternal and child undernutrition: global and regional exposures and health consequences. Lancet. 2008;371(9608):243-60. https://doi.org/10.101 6/S0140-6736(07)61690-0.

5. Black MM, Walker SP, Fernald LCH, Andersen CT, DiGirolamo AM, Lu C, et al. Early childhood development coming of age: science through the life course. Lancet. 2017;389(10064):77-90. https://doi.org/10.1016/S0140-6736(1 6)31389-7.

6. Grantham-McGregor S, Cheung YB, Cueto S, Glewwe P, Richter L, Strupp B. Developmental potential in the first 5 years for children in developing countries. Lancet. 2007;369(9555):60-70. https://doi.org/10.1016/S0140-673 6(07)60032-4.

7. Hoddinott J, Behrman JR, Maluccio JA, Melgar P, Quisumbing AR, RamirezZea $M$, et al. Adult consequences of growth failure in early childhood. Am J Clin Nutr. 2013;98(5):1170-8. https://doi.org/10.3945/ajen.113.064584.

8. Victora CG, de Onis M, Hallal PC, Blossner M, Shrimpton R. Worldwide timing of growth faltering: revisiting implications for interventions. Pediatrics. 2010;125(3):e473-80. https://doi.org/10.1542/peds.2009-1519.

9. Black RE, Victora CG, Walker SP, Bhutta ZA, Christian P, de Onis M, et al. Maternal and child undernutrition and overweight in low-income and middle-income countries. Lancet. 2013; Epub: 2013/06/12.

10. Victora CG, Adair L, Fall C, Hallal PC, Martorell R, Richter L, et al. Maternal and child undernutrition: consequences for adult health and human capital. Lancet. 2008;371(9609):340-57. https://doi.org/10.1016/S0140-6736(07)61 692-4.

11. Prentice AM, Ward KA, Goldberg GR, Jarjou LM, Moore SE, Fulford AJ, et al. Critical windows for nutritional interventions against stunting. Am J Clin Nutr. 2013;97(5):911-8. https://doi.org/10.3945/ajen.112.052332.

12. Lundeen EA, Behrman JR, Crookston BT, Dearden KA, Engle P, Georgiadis A, et al. Growth faltering and recovery in children aged 1-8 years in four lowand middle-income countries: young lives. Public Health Nutr. 2014;17(9): 2131-7. https://doi.org/10.1017/S1368980013003017.

13. Anand P, Behrman JR, Dang HH, Jones S. Varied patterns of catch-up in child growth: evidence from young lives. Soc Sci Med. 2018;214:206-13. https://doi.org/10.1016/j.socscimed.2018.07.003.

14. Fink G, Rockers PC. Childhood growth, schooling, and cognitive development: further evidence from the young lives study. Am J Clin Nutr. 2014;100(1):182-8. https://doi.org/10.3945/ajcn.113.080960.

15. Zhang R, Undurraga EA, Zeng W, Reyes-Garcia V, Tanner S, Leonard WR, et al. Catch-up growth and growth deficits: nine-year annual panel child growth for native Amazonians in Bolivia. Ann Hum Biol. 2016;43(4):304-15. https://doi.org/10.1080/03014460.2016.1197312.

16. Leroy JL, Ruel M, Habicht JP, Frongillo EA. Using height-for-age differences (HAD) instead of height-for-age z-scores (HAZ) for the meaningful measurement of population-level catch-up in linear growth in children less than 5 years of age. BMC Pediatr. 2015;15(1):145. https://doi.org/10.1186/s12 887-015-0458-9.

17. Leroy JL, Ruel $M$, Habicht JP, Frongillo EA. Linear growth deficit continues to accumulate beyond the first 1000 days in low- and middle-income countries: global evidence from 51 national surveys. J Nutr. 2014;144(9): 1460-6. https://doi.org/10.3945/jn.114.191981.

18. Lundeen EA, Stein AD, Adair LS, Behrman JR, Bhargava SK, Dearden KA, et al. Height-for-age z scores increase despite increasing height deficits among children in 5 developing countries. Am J Clin Nutr. 2014;100(3):8215. https://doi.org/10.3945/ajcn.114.084368.

19. Investigators MAL-ED. The MAL-ED study: a multinational and multidisciplinary approach to understand the relationship between enteric pathogens, malnutrition, gut physiology, physical growth, cognitive development, and immune responses in infants and children up to 2 years of age in resource-poor environments. Clin Infect Dis. 2014;59(Suppl 4): S193-206.

20. Richard SA, McCormick BJJ, Murray-Kolb LE, Lee GO, Seidman JC, Mahfuz M, et al. Enteric dysfunction and other factors associated with attained size at 5 y: MAL-ED birth cohort study findings. AJCN. 2019;00:1-8.

21. Richard SA, Barrett $L$, Guerrant RL, Checkley W, Miller MA, Investigators M-EN. Disease surveillance methods used in the 8-site MAL-ED cohort study. Clin Infect Dis. 2014;59(Suppl 4):S220-4. https://doi.org/10.1093/ cid/ciu435.

22. Caulfield LE, Bose A, Chandyo RK, Nesamvuni C, de Moraes ML, Turab A, et al. Infant feeding practices, dietary adequacy, and micronutrient status measures in the MAL-ED study. Clin Infect Dis. 2014;59(Suppl 4):S248-54. https://doi.org/10.1093/cid/ciu421.

23. Kosek M, Guerrant RL, Kang G, Bhutta Z, Yori PP, Gratz J, et al. Assessment of environmental enteropathy in the MAL-ED cohort study: theoretical and analytic framework. Clin Infect Dis. 2014;59(Suppl 4):S239-47. https://doi. org/10.1093/cid/ciu457.

24. Houpt E, Gratz J, Kosek M, Zaidi AK, Qureshi S, Kang G, et al. Microbiologic methods utilized in the MAL-ED cohort study. Clin Infect Dis. 2014;59(Suppl 4):S225-32. https://doi.org/10.1093/cid/ciu413.

25. WHO. WHO Child Growth Standards: Length/height-for-age, weight-for-age, weight-for-length, weight-for-height and body mass index-for-age: methods and development. Geneva: World Health Organization; 2006.

26. Psaki SR, Seidman JC, Miller M, Gottlieb M, Bhutta ZA, Ahmed T, et al. Measuring socioeconomic status in multicountry studies: results from the eight-country MAL-ED study. Popul Health Metrics. 2014;12(1):8. https://doi. org/10.1186/1478-7954-12-8.

27. Platts-Mills JA, Babji S, Bodhidatta L, Gratz J, Haque R, Havt A, et al. Pathogen-specific burdens of community diarrhoea in developing countries: a multisite birth cohort study (MAL-ED). Lancet Glob Health. 2015;3(9):e564-75. https://doi.org/10.1016/S2214-109X(15)001 51-5.

28. Kosek MN, Lee GO, Guerrant RL, Haque R, Kang G, Ahmed T, et al. Age and sex normalization of intestinal permeability measures for the improved assessment of enteropathy in infancy and early childhood: results from the MAL-ED study. J Pediatr Gastroenterol Nutr. 2017;65(1):31-9. https://doi. org/10.1097/MPG.0000000000001610.

29. Willett W, Stampfer MJ. Total energy intake: implications for epidemiologic analyses. Am J Epidemiol. 1986;124(1):17-27. https://doi.org/10.1093/ oxfordjournals.aje.a114366.

30. Rohner F, Namaste SM, Larson LM, Addo OY, Mei Z, Suchdev PS, et al. Adjusting soluble transferrin receptor concentrations for inflammation: Biomarkers Reflecting Inflammation and Nutritional Determinants of Anemia (BRINDA) project. Am J Clin Nutr. 2017;106(Suppl 1):372S-82S. https://doi.org/10.3945/ajcn.116.142232.

31. MAL-ED Investigators. Childhood stunting in relation to the pre- and postnatal environment during the first 2 years of life: the MAL-ED longitudinal birth cohort study. PLoS Med. 2017;14(10):e1002408.

32. MAL-ED Investigators. Relationship between growth and illness, enteropathogens and dietary intakes in the first 2 years of life: findings from the MAL-ED birth cohort study. BMJ Glob Health. 2017;2(4): e000370.

33. Roth DE, Krishna A, Leung M, Shi J, Bassani DG, Barros AJD. Early childhood linear growth faltering in low-income and middle-income countries as a whole-population condition: analysis of 179 demographic and health surveys from 64 countries (1993-2015). Lancet Glob Health. 2017;5(12):e1249-e57. https://doi.org/10.1016/ S2214-109X(17)30418-7.

34. Victora CG, de Onis M, Shrimpton R. Linear growth faltering should be assessed in absolute and relative terms. J Nutr. 2014;144(12):2092-3. https:// doi.org/10.3945/jn.114.200543. 
35. Addo OY, Stein AD, Fall CH, Gigante DP, Guntupalli AM, Horta BL, et al. Maternal height and child growth patterns. J Pediatr. 2013;163(2):549-54. https://doi.org/10.1016/j.jpeds.2013.02.002.

36. Kosek MN, MAL-ED Network Investigators. Causal pathways from

enteropathogens to environmental enteropathy: findings from the MAL-ED birth cohort study. EBioMedicine. 2017;18:109-17. https://doi.org/10.1016/j. ebiom.2017.02.024.

37. Michaelsen KF, Greer FR. Protein needs early in life and long-term health. Am J Clin Nutr. 2014;99(3):718S-22S. https://doi.org/10.3945/ajcn.113.072 603.

\section{Publisher's Note}

Springer Nature remains neutral with regard to jurisdictional claims in published maps and institutional affiliations.

Ready to submit your research? Choose BMC and benefit from:

- fast, convenient online submission

- thorough peer review by experienced researchers in your field

- rapid publication on acceptance

- support for research data, including large and complex data types

- gold Open Access which fosters wider collaboration and increased citations

- maximum visibility for your research: over $100 \mathrm{M}$ website views per year

At BMC, research is always in progress.

Learn more biomedcentral.com/submissions 